\title{
ANALISIS KONDISI PERMUKAAN PERKERASAN JALAN PADA JALAN LEMAHNEUNDEUT DENGAN METODE PCI DAN RCI
}

\author{
Tan Lie Ing ${ }^{1}$, Septa Riana ${ }^{2}$ \\ ${ }^{1}$ DosenProgram Studi S-1 Teknik Sipil, Fakultas Teknik, Universitas Kristen Maranatha \\ ${ }^{2}$ Alumnus Program Studi S-1 Teknik Sipil, Fakultas Teknik, Universitas Kristen Maranatha \\ Jalan Prof. Drg. Suria Sumantri No. 65, Bandung 40164 \\ e-mail: lieing.tan@yahoo.com
}

\begin{abstract}
ABSTRAK
Penilaian kondisi permukaan jalan merupakan salah satu tahapan untuk menentukan jenis program evaluasi yang perlu dilakukan. Dua metode yang dapat digunakan dalam melakukan penilaian kondisi jalan adalah metode Pavement Condition Index dan metode Road Condition Index. Penelitian ini bertujuan untuk membandingkan nilai kondisi ruas jalan Lemahneundeut berdasarkan kedua metode tersebut. Metode yang digunakan adalah penelitian lapangan dengan data berupa hasil survei kerusakan jalan. Urutan prioritas penanganan jalan dengan metode PCI merangking kondisi perkerasan dari nilai 0 hingga 100 sedangkan metode RCI didasarkan pada rentang nilai 0 sampai 10 . Hasil evaluasi kondisi ruas jalan Lemahneundeut dengan metode PCI didapatkan rata-rata nilai PCI adalah 84,785 yang berarti kondisi fungsional jalan sangat baik dan metode RCI sebesar 7,5 yang berarti jalan dalam kondisi permukaan sangat baik dan umumnya rata namun masih memerlukan pemeliharaan yang rutin.
\end{abstract}

Kata kunci: penilaian kondisi jalan, metode PCI, metode RCI

\section{ABSTRACT}

The assessment of pavement condition is needed to establish the appropriate maintenance program. The methods that usually used to evaluate pavement condition are Pavement Condition Index method and Road Condition Index method. This study aims to assess the pavement condition of Lemahneundeut street with these two methods being compared.This study used field research in which the data was the result of pavement condition survey. The priority of pavement maintenance of PCI method rated from 0 to 100 meanwhile the priority of pavement maintenance for RCI method rated from 0 to 10.The evaluation results of the Lemahneundeut road condition with the PCI method found that the average PCI value was 84.785 which meant that the road functional conditions were very good and the RCI method was 7.5 which meant the road was in very good condition and generally flat surface but still needed routine maintenance.

Key words: pavement condition, PCI method, RCI method

\section{PENDAHULUAN}

Manajemen pemeliharaan perkerasan jalan merupakan upaya mempertahankan kondisi jalan sesuai dengan tingkat pelayanan dan kemampuannya pada saat jalan tersebut selesai dibangun dan dioperasikan sampai dengan tercapainya umur rencana yang telah ditentukan. Manajemen pemeliharaan perkerasan jalan dilihat dari jenis kerusakan yang terjadi pada suatu ruas jalan.

Jalan Lemahneundeut, Bandung, merupakan jalan dua lajur satu arah tak terbagi yang menghubungkan antara Jalan Surya Sumantri dan Jalan Terusan Prof. Dr. Sutami. Pada umumnya, umur jalan yang telah direncanakan pada kenyataannya tidak sesuai dengan yang terjadi di lapangan. Seringkali kondisi jalan mengalami kerusakan sebelum 
masa layan jalan tersebut habis. Hal tersebut dapat dipengaruhi oleh beberapa faktor, di antaranya: pertumbuhan lalu lintas yang tidak sesuai prediksi, beban lalu lintas yang melampaui batas (overloading) serta pelaksanaan yang tidak sesuai dengan perencanaan.

Tujuan penelitian adalah mengamati dan mengidentifikasi jenis kerusakan yang terjadi pada permukaan perkerasan ruas Jalan Lemahneundeut dengan menggunakan metode PCI; mengamati dan mengidentifikasi nilai ketidakrataan Jalan Lemahneundeut dengan menggunakan metode RCI; dan menentukan hubungan antara nilai kerusakan permukaan jalan dari metode PCI dan nilai ketidakrataan permukaan dari metode RCI.

\section{STUDI PUSTAKA}

\subsection{Pavement Condition Index}

Penilaian kondisi kerusakan perkerasan ini dikembangkan oleh US. Army Corp of Engineer (Shahin, 1994), dinyatakan dalam indeks kondisi perkerasan (pavement condition index, PCI). Penggunaan PCI untuk perkerasan bandara, jalan, dan tempat parkir telah dipakai secara luas di Amerika. Metode survei dari PCI mengacu pada ASTM D6433 (Standard Practice for Roads and Parking Lots Pavement Condition Surveys).

PCI adalah sistem penilaian kondisi perkerasan jalan berdasarkan jenis, tingkat dan luas kerusakan yang terjadi serta dapat digunakan sebagai acuan dalam usaha pemeliharaan. Tiga tingkat kerusakan yang dapat diidentifikasi oleh metode PCI (Shahin, 1994), yaitu:

1. jenis kerusakan (distress type), yaitu jenis-jenis kerusakan yang secara visual dapat terlihat di permukaan perkerasan. Jenis-jenis kerusakan terbagi atas 19 jenis;

2. tingkat kerusakan (distress severity), yaitu jenis kerusakan yang diidentifikasi sesuai kondisi tipe kerusakan. Tingkat kerusakan ini terbagi atas low (1), medium (m), high (h);

3. jumlah kerusakan (distress amount), berkaitan dengan pengukuran, satuan pengukuran, dan penjumlahan (total) pada formulir survei pada masing-masing tingkat kerusakan.

Pengertian dan istilah-istilah berdasarkan tahapan-tahapan perhitungan pada metode PCI (Lukman, 2014).

1. Survei pendahuluan 
Survei pendahuluan merupakan survei yang harus dilakukan pada awal kegiatan, yaitu sebelum survei detail karena survei detail akan mengacu pada hasil survei. Survei pendahuluan bertujuan untuk mengetahui kondisi umum perkerasan, data geometri, dan jenis-jenis kerusakan yang sering terjadi di lapangan.

2. Pembagian unit sampel

Unit sampel dibagi dalam beberapa unit. Hal ini dilakukan untuk mempermudah dalam pelaksanaan perhitungan dan pengolahan data. Inspeksi dari setiap unit sampel dalam suatu bagian perkerasan yang membutuhkan usaha ekstra, khususnya jika bagiannya besar. Pembagian unit sampel dihitung mengggunakan Persamaan 2.1.

$$
\mathrm{n}=\frac{N s^{2}}{\frac{e^{2}}{4}(N-1)+S^{2}}
$$

dengan:

$\mathrm{n}=$ Jumlah unit sampel

$\mathrm{N}=$ Jumlah total unit sampel dalam suatu bagian perkerasan

e = Kesalahan yang diizinkan dalam estimasi dari bagian PCI ( $\mathrm{e}=5$ ),

$\mathrm{s}$ = Deviasi standar antara unit sampel di dalam bagiannya (untuk AC, $\mathrm{s}=10$ )

Setelah didapatkan jumlah minimum dari unit sampel, ditentukam jarak interval tiap sampel yang dihitung menggunakan Persamaan 2.2 (ASTM D5340-12, 2012).

$$
i=\frac{N}{n}
$$

dengan:

$\mathrm{N}=$ Jumlah total unit sampel satu bagian perkerasan

$\mathrm{n}=$ Jumlah unit sampel minimum

$\mathrm{i}=$ Interval jarak unit-unit sampel

\subsection{Density}

Density atau kadar kerusakan adalah persentase kerusakan terhadap luasan suatu unit segmen yang diukur meter persegi atau meter panjang. Nilai density suatu jenis kerusakan dibedakan juga berdasarkan tingkat kerusakannya. Nilai density dihitung menggunakan Persamaan 2.3 atau Persamaan 2.4.

$$
\text { Density }=\frac{A d}{A \varepsilon} \times 100 \%
$$

atau 


\section{Density $=\frac{E d}{A s} x 100 \%$}

dengan

$\mathrm{Ad}=$ Luas total jenis kerusakan untuk tiap tingkat kerusakan $\left(\mathrm{m}^{2}\right)$

$\mathrm{Ld}=$ Panjang total jenis kerusakan untuk tiap tingkat kerusakan (m)

As $=$ Luas total unit segmen $\left(\mathrm{m}^{2}\right)$

\subsection{Deduct Value}

Deduct value merupakan nilai pengurangan pada setiap jenis kerusakan yang diperoleh dari hubungan antara density dan deduct value.

\subsection{Total Deduct Value}

Total deduct value (TDV) merupakan nilai total dari individual deduct value untuk tiap jenis kerusakan dan tingkat kerusakan yang ada pada suatu unit penelitian.

\subsection{Corrected Deduct Value}

Corrected deduct value (CDV) merupakan nilai yang diperoleh dari kurva hubungan antara nilai TDV dan nilai CDV dengan pemulihan lengkung kurva sesuai dengan jumlah nilai setiap deduct value yang mempunyai nilai lebih besar dari 2 .

\subsection{Nilai Allowable Number of Deduct}

Nilai allowable number of deduct (m) adalah maksimum nilai deduct setiap jenis perkerasan yang diizinkan untuk diperhitungkan di dalam penilaian kondisi perkerasan. Nilai $\mathrm{m}$ dipengaruhi oleh nilai deduct terbesar dalam suatu unit sampel dan dihitung menggunakan Persamaan 2.5.

$$
m_{4}=1+\left(\frac{9}{98}\right)(100-\text { HDVD })
$$

$\mathrm{m}_{\mathrm{i}} \quad=$ Allowable number of deduct setiap unit sampel

HDVi=Highest deduct value, nilai deduct value terbesar pada setiap unit sampel

\subsection{Menentukan Kondisi Perkerasan}

Nilai PCI yang didapatkan kemudian diplot ke dalam diagram nilai PCI sehingga didapatkan kategori kondisi perkerasan pada unit sampel tersebut. Diagram nilai PCI dapat dilihat pada Gambar 2.1.

Analisis Kondisi Permukaan Perkerasan Jalan Pada Jalan Lemahneundeut dengan Metode PCI Dan RCI 


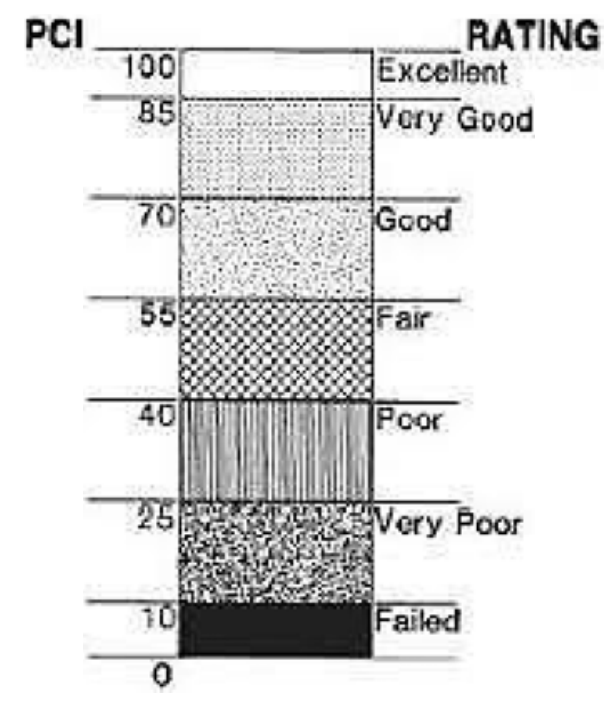

Gambar 2.1 Rating Kondisi Jalan Berdasarkan Metode PCI Somber: Shahin, 1994

\subsection{International Roughness Index}

International roughness index (IRI) merupakan nilai yang menentuk:an nilai kekasaran jalan. Dalam menentukan nilai IRI diperlukan beberapa klasifikasi, klasifikasi nilai IRI dapat dilihat pada Tabel 2.2.

Tabel 2.2 Klasifikasi Nilai IRI

\begin{tabular}{ccc}
\hline Nilai IRI & Tipe Permukaan & Keterangan \\
\hline$<4$ & Aspal & Sangat Baik \\
$4-8$ & Aspal & Cukup Baik \\
$8-12$ & Aspal & Cukup Buruk \\
$12-16$ & Aspal & Buruk \\
$16-20$ & Aspal & Jelek \\
$\geq 20$ & Aspal & Sangat Jelek \\
Lainnya & Tidak Beraspal & - \\
\hline
\end{tabular}

Sumber: Departemen Pekerjaan Umum, 2012

\subsection{Road Condition Index}

Road condition index (RCI) merupakan skala tingkat kenyamanan atau knerja jalan yang dapat diperoleh dengan alat roughometer. Nilai IRI kemudian dikonversi 
untuk mendapatkan nilai RCI. Korelasi antara RCI dengan IRI dirumuskan dalam Persamaan 2.8.

$$
\mathrm{RCI}=10 \times \operatorname{Exp}\left(-0,0501 \times \mathrm{xIRI}^{1,220921}\right)
$$

dengan:

$\mathrm{RCI}=\mathrm{Nilai} \mathrm{RCI}$

IRI $=$ Nilai IRI

\section{METODE PENELITIAN}

Survei dilakukan pada hari Rabu, 11November 2018. Lokasi survey pada Jalan Lemahneundeut, Kelurahan Sukawama, Kecamatan Sukajadi Kota Bandung, sepanjang $450 \mathrm{~m}$ dalam dua lajur satu arah tak terpisah, lebar perkerasan $6,6 \mathrm{~m}$, dan jenis perkerasan yang digunakan adalah perkerasan kaku. Langkah-langkah yang perlu dilakukan dalam metode PCI adalah:

1. survei pendahuluan

Survei pendahuluan bertujuan untuk mengetahui kondisi umum perkerasan, data geometri, dan jenis-jenis kerusakan yang terjadi di lapangan. Data pada survei pendahuluan membantu dalam survei selanjutnya;

2. menentukan unit sampel

Untuk membantu penelitian dan pengolahan data, diperlukan pembagian beberapa unit sampel. Data pra survei kondisi jalan dapat dilihat pada Tabel 3.1;

Tabel 3.1 Data Pra Survei Kondisi Jalan Keterangan Nilai

\begin{tabular}{lc}
\hline \multicolumn{1}{c}{ Keterangan } & Nilai \\
\hline Panjang area survei & $450 \mathrm{~m}$ \\
Panjang sampel & $10 \mathrm{~m}$ \\
Lebar jalan & $6,6 \mathrm{~m}$ \\
Luas sampel & $66 \mathrm{~m}^{2}$ \\
Kesalahan yang diizinkan dalam & 5 \\
estimasi (e) & \\
Deviasi standar (s) & (untuk permukaan lapis perkerasan \\
& dengan lapis beton) \\
\hline
\end{tabular}

Berdasarkan Tabel 3.1, unit sampel $(\mathrm{N})=45$, deviasi standar (s) untuk perkerasan $\mathrm{kaku}=10$, dan nilai kesalahan yang diizinkan $(\mathrm{e})=5$, maka didapat jumlah minimum unit sampel yang ditinjau dengan menggunakan Persamaan 2.1 adalah 12 sampel.

Analisis Kondisi Permukaan Perkerasan Jalan Pada Jalan Lemahneundeut dengan Metode PCI Dan RCI 
1. pemilihan jumlah minimum unit sampel yang harus disurvei

Setelah didapatkan jumlah minimum dari unit sampel, dilakukan pemilihan unit sampel dengan menggunakan Persamaan 2.2;

$$
t=\frac{48}{12}=3,75 \approx 4
$$

Maka, pemilihan unit sampel dilakukan secara acak sehingga didapatkan jumlah sampel yang akan ditinjau sebanyak 12 sampel seperti pada Tabel 3.2;

Tabel 3.2 Pembagian Potongan Unit Sampel

\begin{tabular}{|c|c|c|c|c|c|c|c|c|c|}
\hline 1 & 2 & 3 & 4 & 5 & 6 & 7 & 8 & 9 & 10 \\
\hline $10 \mathrm{~m}$ & $10 \mathrm{~m}$ & $10 \mathrm{~m}$ & $10 \mathrm{~m}$ & $10 \mathrm{~m}$ & $10 \mathrm{~m}$ & $10 \mathrm{~m}$ & $10 \mathrm{~m}$ & $10 \mathrm{~m}$ & $10 \mathrm{~m}$ \\
\hline
\end{tabular}

\begin{tabular}{|c|c|c|c|c|c|c|c|c|c|}
\hline 11 & 12 & 13 & 14 & 15 & 16 & 17 & 18 & 19 & 20 \\
\hline $10 \mathrm{~m}$ & $10 \mathrm{~m}$ & $10 \mathrm{~m}$ & $10 \mathrm{~m}$ & $10 \mathrm{~m}$ & $10 \mathrm{~m}$ & $10 \mathrm{~m}$ & $10 \mathrm{~m}$ & $10 \mathrm{~m}$ & $10 \mathrm{~m}$ \\
\hline
\end{tabular}

\begin{tabular}{|c|c|c|c|c|c|c|c|c|c|}
\hline 21 & 22 & 23 & 24 & 25 & 26 & 27 & 28 & 29 & 30 \\
\hline $10 \mathrm{~m}$ & $10 \mathrm{~m}$ & $10 \mathrm{~m}$ & $10 \mathrm{~m}$ & $10 \mathrm{~m}$ & $10 \mathrm{~m}$ & $10 \mathrm{~m}$ & $10 \mathrm{~m}$ & $10 \mathrm{~m}$ & $10 \mathrm{~m}$ \\
\hline
\end{tabular}

\begin{tabular}{|c|c|c|c|c|c|c|c|c|c|}
\hline 31 & 32 & 33 & 34 & 35 & 36 & 37 & 38 & 39 & 40 \\
\hline $10 \mathrm{~m}$ & $10 \mathrm{~m}$ & $10 \mathrm{~m}$ & $10 \mathrm{~m}$ & $10 \mathrm{~m}$ & $10 \mathrm{~m}$ & $10 \mathrm{~m}$ & $10 \mathrm{~m}$ & $10 \mathrm{~m}$ & $10 \mathrm{~m}$ \\
\hline
\end{tabular}

\begin{tabular}{|c|c|c|c|c|}
\hline 41 & 42 & 43 & 44 & 45 \\
\hline $10 \mathrm{~m}$ & $10 \mathrm{~m}$ & $10 \mathrm{~m}$ & $10 \mathrm{~m}$ & $10 \mathrm{~m}$ \\
\hline
\end{tabular}

2. menetapkan deduct value

a. menghitung total tiap-tipe kerusakan pada masing-masing tingkat kerusakan;

b. menentukan deduct value untuk masing-masing tipe kerusakan dan kombinasi tingkat kerusakan berdasarkan kurva penentuan deduct value;

3. menentukan nilai izin dari deduct

a. jika hanya satu deduct value dengan nilai $>5$ untuk bandara dan $>2$ untuk jalan, maka total deduct value digunakan sebagai corrected deduct value, jika tidak maka dilanjutkan pada tahap berikutnya;

b. mengurutkan deduct value dari nilai terbesar;

c. menentukan nilai $\mathrm{m}$;

d. masing-masing deduct value dikurangkan terhadap $\mathrm{m}$, jika jumlah hasil pengurangan lebih kecil dari maka semua deduct value dapat dipergunakan;

4. menentukan CDV maksimum

a. menentukan jumlah nilai deduct yang lebih besar dari 5 (q);

b. menentukan nilai total dari deduct dengan menjumlahkan tiap nilai deduct; 
c. menentukan CDV dari perhitungan a dan $b$, dengan menggunakan kurva korelasi nilai deduct;

d. CDV maksimum adalah CDV terbesar pada proses iterasi;

5. menghitung nilai PCI.

\section{ANALISIS DAN PEMBAHASAN}

\subsection{Menghitung Nilai PCI}

Berikut merupakan contoh perhitungan PCI untuk sampel ke-2:

$$
\begin{aligned}
\mathrm{PCI}_{(\mathrm{S})} & =100-29 \\
& =71(\text { Very good })
\end{aligned}
$$

Tabel 4.1 Nilai PCI Jalan Lemahneundeut

\begin{tabular}{ccccccc}
\hline $\begin{array}{c}\text { No } \\
\text { Sampel }\end{array}$ & $\begin{array}{c}\text { Titik } \\
\text { awal }\end{array}$ & TDV & $\mathbf{q}$ & CDV & PCI & Kondisi \\
\cline { 2 - 3 } & $\mathbf{m})$ & & & & & \\
\hline 1 & 0 & 0,3 & 1 & 0 & 100 & Excellent \\
2 & 20 & 29 & 1 & 29,00 & 71 & Very good \\
& & 0 & 1 & 0 & 100 & Excellent \\
3 & 40 & 32 & 1 & 32,00 & 68 & Good \\
& & 27 & 1 & 2700 & 73 & Very good \\
4 & 60 & 27 & 1 & 27,00 & 73 & Very good \\
5 & 80 & & 1 & 0 & 100 & Excellent \\
& 100 & 20 & 1 & 20,00 & 80 & Very good \\
6 & 120 & 25,5 & 1 & 25,50 & 74,5 & Very good \\
7 & 140 & 28 & 1 & 28,00 & 72 & Very good \\
8 & 160 & 30 & 1 & 30,00 & 70 & Good \\
9 & 180 & 21 & 1 & 21,00 & 79 & Very good \\
10 & 200 & 26 & 1 & 26,00 & 74 & Very good \\
11 & & 0 & 1 & 0 & 100 & Excellent \\
12 & 220 & 30 & 1 & 30,00 & 70 & Good \\
\hline
\end{tabular}

Dari data yang didapat secara keseluruhan pada seluruh unit sampel maka didapatkan rata-rata nilai PCI sebesar 84,785 yang berarti kondisi fungsional perkerasan adalah sangat baik (very good). 


\subsubsection{Metode RCI}

Pada metode RCI diperlukan beberapa parameter yang harus ditentukan terlebih dahulu untuk mempermudah mendapatkan nilai RCI. Beberapa parameter yang diperlukan.

\subsubsection{Penentuan Nilai RCI}

Pada analisis data sebelumnya diketahui bahwa nilai PCI rata-rata untuk jalan Lemahneundeut sebesar 84.285, jadi nilai RCI berada di antara interval angka 7-8, maka didapatkan nilai RCI sebesar 7,5.

\subsection{Pembahasan}

Berdasarkan hasil analisis diketahui bahwa ruas Jalan Lemahneundeut memiliki nilai PCI $=84,785$ yang berarti kondisi fungsional perkerasan adalah sangat baik (very good), dan nilai $\mathrm{RCI}=7,5$ yang berarti sangat baik dan umumnya permukaan rata. Hal ini menunjukkan bahwa ruas jalan Lemahneundeut secara keseluruhan masih memiliki kondisi permukaan sangat baik dan teratur serta fungsi pelayanan yang baik. Rekonstruksi perbaikan jalan masih belum diperlukan, namun pemeliharaan jalan masih perlu dibutuhkan sesuai dengan gejala kerusakan setiap segmen pada sampel. Kerusakan jalan Lemahneundeut dapat diakibatkan oleh masalah pada sistem drainase serta letak geografis jalan berada pada cekung dan cembung yang cukup curam sehingga kerusakan keriting (corrugation) pada permukaan sering terjadi.

Dari analisis nilai tingkat kerusakan Jalan Lemahneundeut maka diketahui hubungan antara metode PCI dan metode RCI bahwa tingkat baik atau buruknya kerusakan pada permukaan perkerasan jalan dengan metode PCI bernilai sepuluh kali lipat dari nilai tingkat kekasaran permukaan perkerasan jalan yang dihasilkan metode RCI.

\section{SIMPULAN}

Berdasarkan hasil analisis data dan pembahasan, maka dapat disimpulkan bahwa:

1. secara keseluruhan terdapat 4 tingkat kerusakan pada Jalan Lemahneundeut, antara lain: bergelombang, retak reflektif sambungan jalan, retak memanjang/melintang, dan kerusakan akibat tambalan dan tambalan galian utilitas.

2. nilai rata-rata yang didapat untuk metode PCI adalah 84,285 . Dari nilai rata-rata tersebut dapat ditarik simpulan bahwa kondisi fungsional perkerasan jalan Lemahneundeut sangat baik (very good). 
3. nilai yang didapat untuk metode RCI adalah 7,5 , artinya jalan dalam kondisi sangat baik dan umumnya permukaan rata.

4. dari hasil analisis metode PCI dan metode RCI diketahui hubungan antara metode PCI dan metode RCI bahwa tingkat baik atau buruknya kerusakan pada permukaan perkerasan jalan dengan metode PCI bernilai sepuluh kali lipat dari nilai tingkat kekasaran permukaan perkerasan jalan yang dihasilkan metode RCI.

\section{DAFTAR PUSTAKA}

1. ASTM Designation D6433, 2007, Standard Practice for Roads and Parking Lots Pavement Condition Index Surveys.

2. Departemen Pekerjaan Umum, 2007, Panduan Survei Kekasaran Permukaan Jalan Secara Visual.

3. Departemen Pekerjaan Umum, 1987, Petunjuk Perencanaan Tebal Perkerasan Lentur Jalan Raya Dengan Metode Analisa Komponen. Direktorat Jendral Bina Marga, Jakarta.

4. Departemen Pekerjaan Umum, 1997, Tata Cara Perencanaan Geometri Jalan Antar Kota No.038/tbm/1997, Direktorat Jenderal Bina Marga, Jakarta.

5. Shahin, M., 1994, Pavement Management for Airport, Roads, and Parking Lots, Chapman and Hill, New York.

6. Suherman, 2008, Studi Persamaan Korelasi Antara Ketidakrataan Permukaan Jalan dengan Indeks Kondisi Jalan, Jurnal Teknik Sipil Politeknik Negeri Bandung, Bandung.

7. Sukirman, S., 1992, Perkerasan Lentur Jalan Raya, Nova, Bandung. 